\title{
STANDARD INDUSTRIAL INVERTER CONTROLLED DRIVE CHAIN FOR VARIOUS TYPE OF EV
}

\author{
István BARTHA \\ Electrical Engineering and \\ Mechatronics Department \\ University of Debrecen, Faculty of \\ Engineering \\ Debrecen, Hungary \\ bartha@eng.unideb.hu
}

\author{
Attila VITÉZ \\ Electrical Engineering and \\ Mechatronics Department \\ University of Debrecen, Faculty of \\ Engineering \\ Debrecen, Hungary \\ viteza@eng.unideb.hu
}

\author{
Dr. Géza HUSI \\ Electrical Engineering and \\ Mechatronics Department \\ University of Debrecen, Faculty of \\ Engineering \\ Debrecen, Hungary \\ husigeza@eng.unideb.hu
}

\begin{abstract}
Nowdays electric mobility is a progressive field of vehicle technique. Almost all of the well known manufacturers (such as Opel, Toyota, Citroen etc.) has their own type of electric passenger car, more of them is hybrid. With a patented driving chain, we have a versatile traction system, which is cheap, efficient, and easy to implement almost any type of electric vehicle (such as passenger cars, public transportation /busses/, vans, trucks or even as small as electric bikes.
\end{abstract}

Keywords- Electric Vehicle, AC inverter, induction motor, ribcage induction motor.

\section{INTRODUCTION}

In the last decade, the number of electrically driven vehicle is growing rapidly. Not just because of the depletion of fossil fuels. In most countries people have changed their mind to use green energy not only in their households, but for their cars as well. However the electric traction system is very expensive to implement for a normal combustion engine used car. Also a great problem is that the energy carried in a normal gas tank is much more, and it is easier to refill than in case of a battery. In case of high energy density batteries, the safe storage of the units is also a very difficult problem. Therefore, we started to develop a new, easy to implement and cheap traction system for electric vehicle in 2010, in the University of Debrecen, Faculty of Engineering, Electrical Engineering and Mechatronics Department.

\section{PRELIMINARY CONSIDERATIONS}

Most of the electric vehicles has a DC energy system. The power of the traction is a dc battery, and a brushless, or brushed motor assure the traction force for the vehicle. Like all electric motors or generators, torque (traction force) is produced by the principle of Lorentz force. Advantages of a brushed DC motor include low initial cost, high reliability, and simple control of motor speed (i.e.: The tension of the motor contacts is proportional to the motor speed). Disadvantages are high maintenance and low life-span for high intensity uses. Maintenance involves regularly replacing the brushes and springs which carry the electric current, as well as cleaning or replacing the commutator. These components are necessary for transferring electrical power from outside the motor to the spinning wire windings of the rotor inside the motor. Typical brushless DC motors use a rotating permanent magnet in the rotor, and stationary electrical current/coil magnets on the motor housing for the rotor, but the symmetrical opposite is also possible. A motor controller converts DC to AC. This design is simpler than that of brushed motors because it eliminates the complication of transferring power from outside the motor to the spinning rotor. Advantages of brushless motors include long life span, little or no maintenance, and high efficiency. Disadvantages include high initial cost, more complicated motor speed controllers, and difficult to manage the charging of the batteries under braking. It is also possible to use normal AC synchronous motor as the drive of the vehicle. It works like brushless DC motors, but the input characteristic of the tension is not a trapezoid function, but a sine or quasy-sine wave. The advantages of such a motor is the same as the BLDC. It has even better starting characteristic than the BLDC. Disadvantage is that the controller circuit is very dedicated for a single unit, because of the speciality of input wave. Both type of synchronous and BLDC motor needs a very accurate position and angle determination, which can be a difficult task during high vibration circumstances.

\section{AC TRACTION SYSTEM}

This well known traction system, mentioned above, can be implement able to any kind of application if someone has enough manpower and money. But in most cases on of the above mentioned components is not available. Four years ago, we had the opportunity to take part in a race competition for alternatively driven vehicles. In cooperation with our Mechanical Engineering department, we built a race car. But the performance of a normal hub motor was not good enough 
to reach the top speed, and energy consumption, we decided. So came an idea to use industrial AC rib-cage induction motor. Advantage of such a motor include low initial cost, high reliability, high life-span, low maintenance cost. Disadvantages are very low initial torque, difficult controlling system, when it is individually built.

\section{INDUSTRIAL AC INVERTER}

The disadvantages of the AC motor can be negligible, if we use an industrial inverter fed trough directly its DC-bus in an open loop controlling mode (Fig.1.).

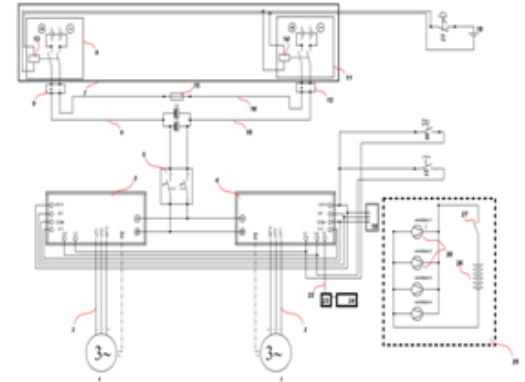

\section{Theoretical connection of our AC traction system}

All of the standard industrial inverters are capable of handling smaller AC motor then its nominal value, so we decided to use two $4.4 \mathrm{~kW}$ AC motor directly connected to the shaft of the back wheels, without any gear.

Because of the working principal of a normal ribcage induction motor, it is difficult to start the car with such a huge amount of torque, to start the motor spinning. However, the inverter can transform the incoming energy in such a way, that the induction motor can deliver 10 times more torque, than its nominal maximum, even in the very low rpm range.

This is the pinpoint of our patented traction system, because in such circumstances the ribcage motor produce so much heat, that its own cooling system is not enough. Therefore we planed to cool our motor with an inner air cooling system, made of high airflow rotor. Later on, during test runs, we found, that such kind of air cooling system is not enough. So with a twist, we put the whole running motor into normal transformer oil. We decided to make some circulation with the spinning rotor of the induction motor. We managed to connect the hydraulic system, with sufficient cooler area (an oil cooler net area of $900 \mathrm{~cm}^{2}$ ). The circulation through the hydraulic circuit has been granted by gravitational circulation.

With such a cooling system, we could increase the performance of our traction system, and our race car as well, with reasonable power consumption.

\section{BUILDING BLOCKS, AND CONSTRUCTION}

\section{A. Mechanical construction}

The main chassis of our race car can be seen on Fig. 2. It was built in the workshop of our Mechanical Engineering
Department, by final year students. One of them was our driver during the first race. It was made of high grade aluminum tube, manufactured, and welded together. There are four different flying arms, with very small spring length, because the clearance of the car designed to $3 \mathrm{~cm}$ from the ground. The two back wheels are connected to the driving AC motor directly without any gear, which is the main point of the invention. Because of weight limitation in the rules of the mentioned race, there were essential to eliminate every heavy parts of a normal traction system. The gearbox is such a thing, and there were not enough space to use a light sprocket wheel and chain. The producer of the motor told us, that there is impossible to start the motor without any gear.

\section{B. Electrical construction}

Another pinpoint of our invention is the usage of normal industrial inverter. The unit, we have used is a Schneider Electric produced ATV71 unit, with 240 VAC input voltage at 3 phase. The nominal voltage of DC bus rail of this type of inverter is 320 VDC. It was a difficult task, to find a proper type of battery pack for such a voltage. There was also a huge problem, to find the best energy density / power density ration in a given battery pack. This inverter has a nominal power of $5.5 \mathrm{~kW}$. Two of these inverter were used in a master-slave operation. Therefore, we needed $13 \mathrm{kWh}$ energy stored in the battery packs, for a 1.5 hour long race. It has turned out during the firs tests, that the inverter unit (and therefore the whole traction system) can be easily driven throughout not only a 1.5 hour race, but almost twice in time.

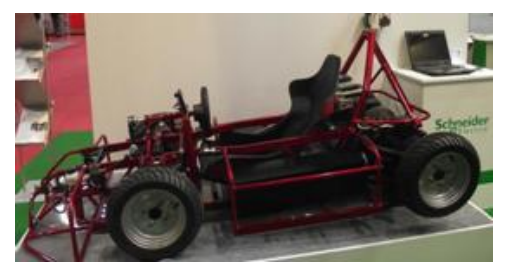

Fig. 2. Physical construction of the main chassis

\section{ENERGY REGENERATION}

In ribcage induction motor it is easy to reach the regeneration (the generator mode). This is because of the working principle of such a device. If you apply some mechanical torque to the shaft of the motor, and make electrical load to the terminals, there will be current flow in the ribcage of the motor by Lorentz force. Having excited the rotor, also current starting to flow in the stator. Defining the spinning speed of the motor by changing the load, we can control the output voltage of the motor terminals. Fortunately, the inverter has built in functions to make a ribcage motor braking. This braking has been accomplished by the way we described above. In a normal application, (for example, to stop the falling weight of a crane, braking resistors has been installed to dissipate the energy coming from the braking of the induction motor. Using the battery pack as a "braking resistor" was a very obvious solution. Therefore, we switched on the braking, and we get the regeneration as a yield of our special traction system. In some preliminary tests, (without 
battery pack) there was a problem to cool the braking resistor. After connecting the batteries, the drive charge the batteries directly, and the braking resistor remain cold. Because of the working of the induction motor, it can generate as much power, as we apply during the acceleration phase. Therefore the efficiency of regeneration is relatively high (approximately, because of the direct connection between the tire and the motor, $85 \%-95 \%$, it depends only the contact force between the tires and the road).

\section{CONTROLLING METHODS}

\section{A. Controlling via speed reference}

A normal passenger car can be controlled, by pressing the throttle pedals. Because of the working principal of a combustion engine, this is a torque control method. The amount of fuel and air mixture is directly proportional to the torque of the combustion engine. However, there is existing a method in the automation industry, where directly the speed of the main shaft (speed of the car in a given gear ratio) has been controlled by the inverter. In such a method only the speed of the spinning shaft can be controlled by external reference. To reach the desired level, the inverter can adjust the load current (which is proportional to the torque of the induction motor) up to 10 times than the nominal value, giving an extremely high torque. In a closed loop control method, we can control both the speed and the torque of the motor in the same time by using an incremental encoder. The technique of such a control method is well described. We decided to make our traction system as simple as possible therefore we used an open loop control method without any encoder. In first test runs, there were a problem of using speed reference, because in normal industrial circumstances it is rarely possible to spin the motor freely, but ready to start any moments. In the automation industry it is often to let our wheels run freely, then in a given moment we need maximum acceleration. The inverter can calculate the actual spinning speed by measuring the electromagnetic back effect of the motor. Naturally, this effect is much less in such a ribcage motor than in case of a permanent magnet mounted rotor, but still enough to calculate the speed. With a special set of internal parameters, we can managed to control our induction motor to get the best performance in driving, which was almost similar to a normal combustion-engine-mounted passenger car. However the best acceleration of the race car has been measured, when the throttle pedal had been handled with care, and not "on-off style".

\section{B. Controlling via torque reference}

In Altivar 71 inverter, there is a possibility to use torque reference instead of speed also in open loop mode. Te internal controller of the inverter calculate the torque of the motor from the load current, which is proportional to the torque. Giving such a reference of the race car, we get a much more "combustion engine effect" of our driving. Controlling the torque reference by pressing and releasing the throttle pedal is more accurate than was the previous method. However, in race conditions it was a bit difficult to avoid of the free spinning of the tire in a curve. It is difficult to make the internal setup of the inverter to do as much regeneration as was it in the speed controlling mode, in this control method. Therefore in such a controlling system only minimal amount of regeneration can be achieved.

\section{ENERGY REGENERATION}

During planning of our traction system, we calculated, that only 30 minutes of running time possible using only the energy stored in the batteries. Therefore it was essential to make a good setup for a very efficient energy regeneration. Fortunately, there is a common way in the inverter to make a regeneration, as much rate as we put the load on the motor. (i.e. Because of the working principal of the induction motor, the EM back force is available, if we can give some load to the motor in generator region.) There were obvious to use the batteries (which are actually infinitely high load) as the load. Therefore during table top tests it was very difficult to adjust the amount of the regeneration. During test run, we make some circles only using the power of the batteries. It turned out, that approximately needs $500 \mathrm{~W}$ of electrical energy to reach $1.5 \mathrm{~km}$ distance. After, we switched on the maximum amount of regeneration. Because of some timing problem of the communication between the two units, it was difficult to drive, but the electrical energy consumption of the car has been dramatically changed. It turned out, that the car can go $15 \mathrm{~km}$ distance with the same amount of electrical energy. This excess comes from the energy conversion from mechanical energy back to electrical energy. Using large pool of batteries as the energy storing unit, there was no problem to charge back almost whole mechanical energy to the batteries. So the only consumption comes from drag, friction of the tires, and load of the controlling and cooling system.

\section{FINAL RESULTS}

In or three-years research project, we have tested various implementation of our newly developed traction system, which patent pending. We tried synchronous induction motor as well, as a reference for the efficiency. Various controlling methods were tested. We have founded, that such a traction system is as good as a traditional DC motor system in the power consumption and efficiency point of view. But on the other hand, it is much cheaper than a BLDC system, and easier to implement for any kind of vehicles from the bicycle to the truck than the synchronous variation. We will get on the project, finding more implementation and simplifications, to get a product able, efficient and relatively cheap traction system, which can be implement next to any combustion engine as a hybrid, or replace the whole traction to fully electrical if needed. 